\title{
Canscora lucidissima, a Chinese folk medicine, exerts anti-inflammatory activities by inhibiting the phosphorylation of ERK $1 / 2$ in LPS-activated macrophages
}

Qiao-ling Fei ${ }^{1}$, Xiao-yu Zhang ${ }^{1}$, Rui-juan Qi ${ }^{1}$, Yun-feng Huang ${ }^{2}$, Yi-xin Han ${ }^{1}$, Xi-meng Li', Run-lan Cai ${ }^{1}$, Yuan Gao ${ }^{1 *}$ and Yun Qi ${ }^{1 *}$ (D)

\begin{abstract}
Background: Canscora lucidissima (Levl. \& Vaniot) Hand.-Mazz. (C. lucidissima), mainly distributed in southern China, has been shown to be effective in the treatment of inflammatory diseases. However, the underlying mechanism of its anti-inflammatory effect is not fully understood.

Methods: In this study, we investigated the anti-inflammatory mechanism of ethanol extract of C. lucidissima (Cl-EE) in lipopolysaccharide (LPS)-induced inflammatory models. ELISA, real-time PCR, Western blot and luciferase reporter assay were used for the experiments in vitro, and ICR mouse endotoxemia model was used for in vivo test.

Results: Our data showed that Cl-EE reduced the production of NO by down-regulating the mRNA and protein expression of inducible nitric oxide synthase (iNOS) in LPS-activated RAW 264.7 cells. Meanwhile, it potently decreased other proinflammatory mediators, such as TNF-a, IL-6, MCP-1 and IL-1 $\beta$ at the transcriptional and translational levels. Further study indicated that Cl-EE did not affect NF-KB signaling pathway but significantly suppressed the phosphorylation of ERK1/2, rather than JNK or p38. In a LPS-induced endotoxemia mouse model, a single intraperitoneal injection of Cl-EE (75-300 mg/kg) could lower circulatory TNF-a, IL-6 and MCP-1 levels.

Conclusions: Collectively, our results indicated that Cl-EE suppressed the phosphorylation level of ERK1/2 thus reducing the transcription and translation of inflammatory genes, thereby exerted anti-inflammatory activity. This study reveals the anti-inflammatory mechanism of $C$. lucidissima and may provide an effective treatment option for a variety of inflammatory diseases.
\end{abstract}

Keywords: Canscora lucidissima, Lipopolysaccharide (LPS), Macrophages, ERK1/2, Endotoxemia

\section{Background}

As an important pathological process, inflammation occurred in many diseases in response to tissue injuries or host defenses against pathogenic microorganism [1]. In the inflammatory process, key events involve the release of pro-inflammatory cytokines and/or chemokines, etc. [2]. As the defense cells, macrophages play a crucial role in killing pathogen microbes and resulting in activating

\footnotetext{
* Correspondence: ygao@implad.ac.cn; yqi@implad.ac.cn

${ }^{1}$ Institute of Medicinal Plant Development, Chinese Academy of Medical Sciences and Peking Union Medical College, 151 North Ma Lian Wa Road, Haidian District, Beijing 100193, China

Full list of author information is available at the end of the article
}

an arsenal of anti-microbial effectors, and consequently triggering the inflammatory cascade [3]. Lipopolysaccharide (LPS) is a component of the outer membrane of Gram-negative bacteria. It can be regarded as a pathogen-associated molecular pattern and can be recognized by the membrane receptor TLR4 on macrophages, and subsequently leading to the activation of NF- $\mathrm{KB}$ and AP-1 and initiating the transcription of downstream inflammatory cytokines [4].

The IкB kinase (IKK) complex, consisting of IKK $\alpha$, IKK $\beta$ and the regulatory subunit NEMO, plays a vital role in myeloid cells. It is well-documented that $\operatorname{IKK} \beta$, rather than IKK $\alpha[5,6]$, can phosphorylate IкB $\alpha$ and lead 
to its ubiquitination and degradation, thus freeing NF$\kappa \mathrm{B}$ p65 into cell nucleus. Besides, IKK complex activation also causes the polyubiquitination and degradation of NF-кB1 p105 [7], which releases TPL-2 from NF-кB1 p105 inhibition and allows TPL-2 to phosphorylate its substrate MEK [8]. And activated MEK phosphorylates ERK1/2 and activates AP-1 signaling. Moreover, the activated NF- $\mathrm{KB}$ or $\mathrm{AP}-1$ can also translocate into the nucleus and promote the transcription of proinflammatory cytokines, such as inducible nitric oxide synthase (iNOS), TNF- $\alpha$, IL-1 $\beta$, IL- 6 and MCP-1 etc. Although the release of these mediators is a protective response of the immune system to microbial invasion, their excessive production can aggravate inflammation and even threaten life in severe cases. Thus, effective antiinflammatory agents are indispensable to suppress these excessive cytokines [9].

Gentianaceae herb Canscora lucidissima (Levl. \& Vaniot) Hand.-Mazz. (C. lucidissima; Fig. 1) mainly distributes in Guangxi and Guizhou provinces of China. It is widely used by the local residents (Zhuang nationality) for the treatment of inflammation-related diseases, such as acute mastitis, impetigo, trauma injury, wasp and snake bites, etc. [10]. Xanthones, a class of constituents in C. lucidissima, were found to ameliorate acute inflammation, including ear/paw edema swelling and peritoneal capillary permeability [11]. Moreover, congeneric herb Canscora decussate (Roxb.) Schult also exhibits considerably anti-inflammatory activity in vitro and in vivo [12]. Nevertheless, no study focused on the antiinflammatory effect of $C$. lucidissima. The present study aims to evaluate the effects of the ethanol extract of C. lucidissima (Cl-EE) on inflammation in LPS-activated macrophages and the corresponding in vivo model (endotoxemia mice) and further explore the underlying mechanism.

\section{Methods}

\section{Materials and reagents}

DMEM and FBS were produced by Gibco BRL (Grand Island, NY, USA). Mouse TNF- $\alpha$, IL-6 and MCP-1 ELISA kits were obtained from Biolegend (San Diego, CA, USA). Mouse IL-1 $\beta$ ELISA kit was purchased from Excell Technology Co. (Shanghai, China). Antibody against iNOS was obtained from Santa Cruz Biotechnology, Inc. (Santa Cruz, California, USA). Antibodies against JNK, ERK1/2, p38, phospho-JNK (p-JNK), phospho-ERK1/2 (p-ERK1/2), phospho-p38 (p-p38), phospho-IкB $\alpha(\mathrm{p}-\mathrm{I} \kappa \mathrm{B} \alpha)$ and NF-kB p65 were obtained from Cell Signaling Technology (Danvers, CO, USA). Antibodies against $\beta$-actin were obtained from Cwbiotech Co. (Beijing, China). Horseradish peroxidaseconjugated anti-rabbit or anti-mouse IgG secondary antibodies and Histone $\mathrm{H} 3$ polyclonal antibody were obtained from Abclonal Biotechonology Co. Ltd. (Wuhan, Hubei, China). TRIzol ${ }^{\circ}$ Reagent was from Thermo Fisher (Van Allen Way, Carlsbad CA). M-MuLV First Strand cDNA Synthesis Kit and oligonucleotide primers were from Sangon Biotech (Shanghai, China). KAPA SYBR

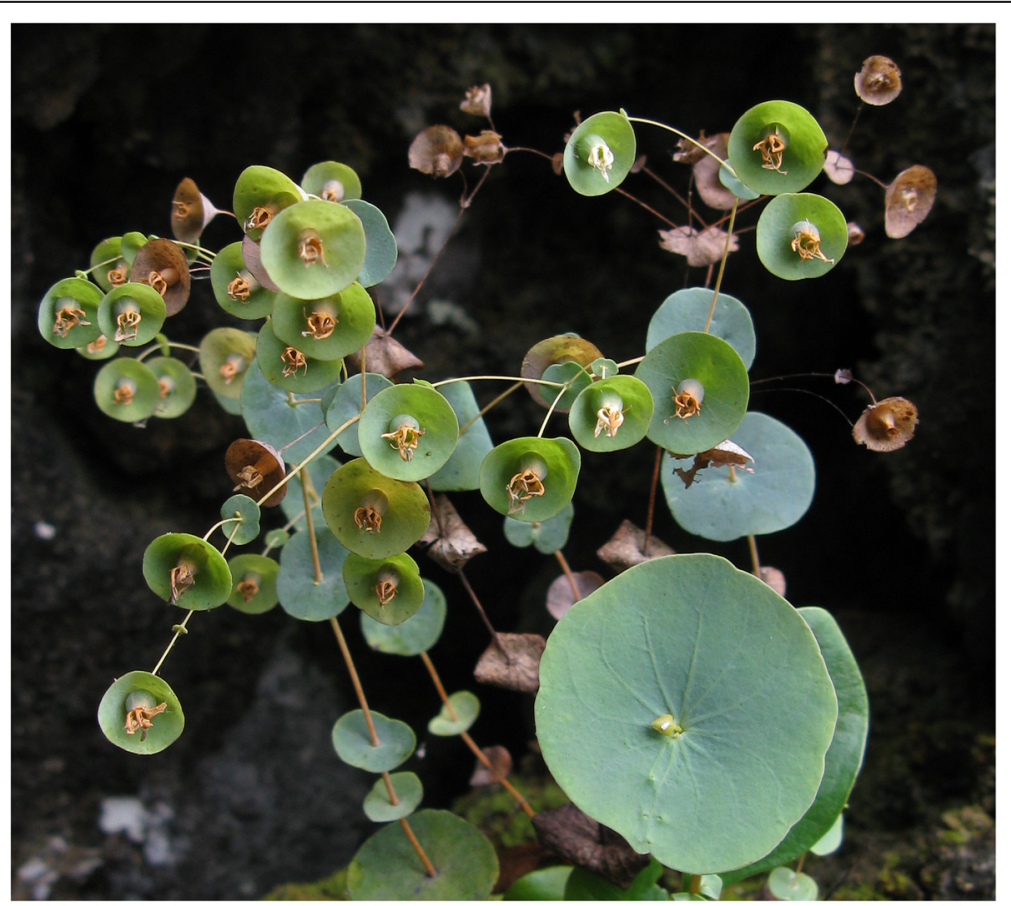

Fig. 1 The original plant of C. lucidissimia obtained from Guangxi province 
FAST Universal 2X qPCR Master Mix kit was obtained from Kapa Biosystems Pty Ltd. (Salt River Cape Town, South Africa). The plasmid for pNFkB-TA-luc and luciferase assay system were from Beyotime Institute of Biotechnology (Haimen, Jiangsu, China). The 3-(4,5-dimethylthiazol-2-yl)-2,5-diphenyl tetrazolium bromide (MTT), L-NG-Nitroarginine Methyl Ester (L-NAME) and LPS were from Sigma-Aldrich (St. Louis, MO, USA). All other reagents were of analytical grade.

\section{Animals}

ICR and C57BL/6 mice (male, 18-20 g) were obtained from Vital River Experimental Animal Services (Beijing, China) and housed in a SPF laboratory under standard temperature $\left(22^{\circ} \mathrm{C}-24^{\circ} \mathrm{C}\right)$ and humidity $(45-65 \%)$ conditions with a $12 \mathrm{~h}$ light/dark cycle and standard pallet diet and water ad libitum. Animal experiments were carried out according to the National Institutes of Health Guide for Care and Use of Laboratory Animals and approved by the Institutional Animal Care and Use Committee (IACUC), Institute of Medicinal Plant Development (IMPLAD) of Chinese Academy of Medical Sciences (CAMS) [SYXK (Beijing) 2007-0020]. Anesthetic drugs and all other necessary measures were used to reduce animal suffering during the experimental procedures.

\section{Preparation of the plant extract}

The herb of C. lucidissima (Fig. 1) from Guangxi Province of China was collected in June 18th 2018. The plant materials were authenticated by Prof. Yun-feng Huang according to their morphological characteristics. A voucher specimen was deposited in the Herbarium of Guangxi Institute of Chinese Medicine \& Pharmaceutical Sciences. Air-dried whole herb of C. lucidissima (100 g) was extracted by an ethanol-water $(85: 15, \mathrm{v} / \mathrm{v}, 2 \mathrm{~L})$ solution for $2 \mathrm{~h}$. The ethanol solvent was removed by rotary evaporator and the thoroughly dried C. lucidissima extract was stored at $-20^{\circ} \mathrm{C}$ with the yield of $28.7 \%$.

\section{Cell isolation, culture and treatment}

The murine macrophage RAW264.7 cell line was obtained from American Type Culture Collection (ATCC, Rockville, MD, USA). Mouse bone marrow-derived macrophages (BMDMs) were obtained from femurs and tibiae of C57BL/6 mice after cervical dislocation and differentiated in 10\% macrophage colony-stimulating factor conditioned media for 5-8 days before use [13]. All cells were cultured in DMEM supplemented with $10 \% \mathrm{FBS}$, penicillin $\mathrm{G}(100$ units $/ \mathrm{mL})$ and streptomycin $(100 \mathrm{mg} / \mathrm{mL})$ in a humidified incubator with $5 \% \mathrm{CO}_{2}$ at $37^{\circ} \mathrm{C}$.

\section{Cell viability assay}

MTT assay was used for the measurement of the effect of Cl-EE on cell viability [14]. Macrophages were seeded in a 96-well plate at a density of $4 \times 10^{5}$ cells per well. After treatment with different concentrations of Cl-EE $(25,50,100,200$ and $400 \mu \mathrm{g} / \mathrm{mL})$ for $20 \mathrm{~h}, 0.5 \%$ MTT was added for a further $4 \mathrm{~h}$. Then, DMSO $(100 \mu \mathrm{L})$ was added into each well and the optical density at $540 \mathrm{~nm}$ was measured by a microplate reader (Thermo Fisher Scientific, USA).

\section{Measurement of NO production}

Supernatant NO production was measured by Griess method [15]. RAW264.7 cells were seeded in a 96-well plate at a density of $4 \times 10^{5}$ cells per well and pretreated with Cl-EE at different concentrations $(25,50$ and $100 \mu \mathrm{g} / \mathrm{mL})$ for $1 \mathrm{~h}$. LPS $(10 \mathrm{ng} / \mathrm{mL})$ was added to the medium for a further incubation. Twenty-four hours later, nitrite production was measured by mixing $100 \mu \mathrm{L}$ of supernatant and $100 \mu \mathrm{L}$ of Griess reagent $[0.1 \%(\mathrm{w} / \mathrm{v})$ $\mathrm{N}$-(1-naphthyl)-ethylenediamine and $1 \%(\mathrm{w} / \mathrm{v})$ sulfanilamide in $5 \%(\mathrm{v} / \mathrm{v})$ phosphoric acid]. Optical density at $540 \mathrm{~nm}$ was measured by a microplate reader.

\section{Measurement of iNOS activity}

The effect of Cl-EE on the iNOS activity was measured as we previously described [16]. RAW264.7 cells were incubated with LPS $(10 \mathrm{ng} / \mathrm{mL})$. Twelve hours later, supernatant LPS was removed by washing three times. In this context, the change of supernatant $\mathrm{NO}$ level is attributed to the change of iNOS enzymatic activity. The LPS-stimulated cells were harvested and plated in a 48well plate at a density of $8 \times 10^{5}$ cells per well and incubated with or without Cl-EE for another $12 \mathrm{~h}$. The iNOS activity was expressed as the nitrite level in the culture medium. A nonselective NOS inhibitor L-NAME was used as a positive control.

\section{Measurement of inflammatory cytokines (TNF- $a$, IL-6, MCP-1 and IL-1 $\beta$ ) in the culture medium}

RAW264.7 cells were seeded at a density of $4 \times 10^{5}$ cells per well in 96-well plates. After the cells were pretreated with $\mathrm{Cl}$-EE at different concentrations for $1 \mathrm{~h}, 10 \mathrm{ng} / \mathrm{mL}$ LPS was added into the medium for another $24 \mathrm{~h}$. Supernatant was collected for determining TNF- $\alpha$, IL- 6 and MCP-1.

Since too low IL-1 $\beta$ production in the supernatant of LPS-activated RAW264.7 cells, BMDMs and higher LPS concentration $(40 \mathrm{ng} / \mathrm{mL})$ were used instead for IL- $1 \beta$ detection. Supernatant cytokines were measured by using ELISA kits according to the manufacturer's instructions.

\section{RNA extraction and quantitative real-time PCR (RT-PCR)}

RT-PCR assay was performed as previously described [17]. RAW264.7 macrophages were seeded in 6-well plates at a density of $1.2 \times 10^{7}$ cells per well overnight. The cells were pretreated with Cl-EE for $1 \mathrm{~h}$ and then exposed to LPS $(10 \mathrm{ng} / \mathrm{mL})$ for a further $4 \mathrm{~h}$. Total RNA 
was extracted by using TRIzol and RT-PCR was performed by using a KAPA SYBR $^{\circ}$ FAST Universal $2 \mathrm{X}$ qPCR Master Mix kit. The cycling conditions were as follows: $95^{\circ} \mathrm{C}$ for $20 \mathrm{~s}, 40$ cycles of $95^{\circ} \mathrm{C}$ for $15 \mathrm{~s}$ and $60^{\circ} \mathrm{C}$ for $20 \mathrm{~s}$. The mRNA levels of iNOS, TNF- $\alpha$, MCP1 , IL- $1 \beta$, and IL- 6 were normalized to GAPDH, a stable housekeeping gene. The primer information used in this study was listed in Table 1.

\section{Luciferase reporter assay}

RAW264.7 macrophages stably transfected with pNFkBTA-luc were seeded in a 24-well plate at a density of $2.5 \times 10^{6}$ cells per well overnight. The cells were preincubated with different concentrations of Cl-EE for $1 \mathrm{~h}$ and then exposed to LPS $(10 \mathrm{ng} / \mathrm{mL})$ for a further $4 \mathrm{~h}$. The cells were lysed and the luciferase activity was measured using a luciferase assay kit.

\section{Western blot analysis}

The Western blot assay was performed as we previously described [15]. RAW264.7 macrophages were pretreated with $\mathrm{Cl}$-EE at the indicated concentrations for $1 \mathrm{~h}$ and then exposed to LPS for different time (ERK1/2/pERK1/2, JNK/p-JNK, p38/p-p38, 15 min; ІкB $\alpha / p-I \kappa B \alpha$, NF-kB p65/Histone, $30 \mathrm{~min}$; iNOS, 24h). Proteins in nucleus or cytoplasm were extracted for the assay. The blots were visualized using enhanced chemiluminescence (Applygen, Beijing, China) and data were analyzed using the Gel Doc EQ System (Bio-Rad, Hercules, USA).

\section{Mouse endotoxemia model}

The in vivo anti-inflammatory effect of Cl-EE was investigated in the mouse endotoxemia model [18]. Forty male ICR mice were randomly divided into five groups $(n=8$ per group): normal control (NC) group, model group ( $1 \mathrm{mg} / \mathrm{kg}$ LPS alone) and three Cl-EE treatment groups $(1 \mathrm{mg} / \mathrm{kg}$

Table 1 Sequences of primers used in the RT-PCR analysis

\begin{tabular}{|c|c|c|}
\hline Targets & Direction & Primer sequences \\
\hline \multirow[t]{2}{*}{ iNOS } & $\mathrm{F}$ & 5'-CTC AGC CCA ACA ATA CAA G-3' \\
\hline & R & $5^{\prime}-\mathrm{CTA}$ CAG TTC CGA GCG TCA-3' \\
\hline \multirow[t]{2}{*}{ IL-6 } & $\mathrm{F}$ & 5'-CTG CAA GAG ACT TCC ATC CAG-3' \\
\hline & R & 5'-AGT GGT ATA GAC AGG TCT GTT GG-3' \\
\hline \multirow[t]{2}{*}{ MCP-1 } & $\mathrm{F}$ & 5'-GCC CCA CTC ACC TGC TGC TAC T-3' \\
\hline & $\mathrm{R}$ & 5'-CCT GCT GCT GGT GAT CCT CTT GT-3' \\
\hline \multirow[t]{2}{*}{$I L-1 \beta$} & $\mathrm{F}$ & 5'-GCA ACT GTT CCT GAA CTC AAC T-3' \\
\hline & $\mathrm{R}$ & 5'-ATC TाT TGG GGT CCG TCA ACT-3' \\
\hline \multirow[t]{2}{*}{ TNF-a } & $\mathrm{F}$ & 5'- GCC TAT GTC TCA GCC TCT T-3' \\
\hline & $\mathrm{R}$ & 5'- GGT TGA CTT TCT CCT GGT AT-3' \\
\hline \multirow[t]{2}{*}{ GAPDH } & $\mathrm{F}$ & 5'-GGT TGT CTC CTG CGA CTT CA-3' \\
\hline & R & 5'-TGG TCC AGG GTT TCT TAC TCC-3' \\
\hline
\end{tabular}

$F$ forward, $R$ reverse
LPS + Cl-EE). Mice were intraperitoneally injected with sterile saline or Cl-EE $(75,150$ and $300 \mathrm{mg} / \mathrm{kg})$. Thirty minutes later, LPS $(1 \mathrm{mg} / \mathrm{kg})$ was intravenously injected to the mice except NC group. Three hours later, the mice were anesthetized by inhalation of isoflurane and the blood samples were collected from the orbital venous plexus. Finally, mice were euthanized by cervical dislocation. The levels of TNF- $\alpha$, IL- 6 and MCP- 1 in serum were measured using ELISA kits.

\section{Statistical analysis}

All data were expressed as mean \pm standard deviation and were analyzed using the one-way ANOVA. The statistical significance was determined by Student's $t$-test for comparisons between two groups. Differences were considered to be significant when $P<0.05$.

\section{Results}

\section{$\mathrm{Cl}$-EE decreases LPS-induced supernatant NO without} cytotoxicity

Cytotoxic assay showed that Cl-EE did not affect the cell viability up to $400 \mu \mathrm{g} / \mathrm{mL}$ (Fig. 2a and Additional file 1: Table S1). Thus, all subsequent in vitro experiments were conducted at nontoxic concentrations $(25-100 \mu \mathrm{g} /$ $\mathrm{mL}$ ). Because a small diffusible molecule NO is a wellknown marker of inflammatory response [19], we first measured the effect of Cl-EE on supernatant NO production in LPS-stimulated RAW 264.7 macrophages. As shown in Fig. 2b and Additional file 1: Table S1, LPS treatment caused a robust increase of supernatant NO, while Cl-EE potently decreased the LPS-induced NO production in a concentration-dependent manner.

\section{$\mathrm{Cl}$-EE suppresses LPS-induced iNOS mRNA and protein expression}

As NO is generated by iNOS in the activated macrophages, we next investigated whether the inhibitory effect of Cl-EE on supernatant $\mathrm{NO}$ was attributed to the down-regulation of iNOS activity or expression in LPSstimulated RAW264.7 cells. As shown in Fig. 3a and Additional file 2: Table S2, the positive control L-NAME significantly inhibited iNOS activity, but Cl-EE could not. We subsequently investigated the effects of Cl-EE on the iNOS mRNA and protein levels. As shown in Fig. $3 \mathrm{~b}$ and $\mathrm{c}$ and Additional file 2: Table S2, treatment with Cl-EE concentration-dependently inhibited the LPS-elevated iNOS expression at both transcriptional and translational levels. Thus, Cl-EE decreased supernatant NO in LPS-activated RAW 264.7 cells via the suppression of iNOS mRNA and protein expression, rather than inhibiting its activity. 


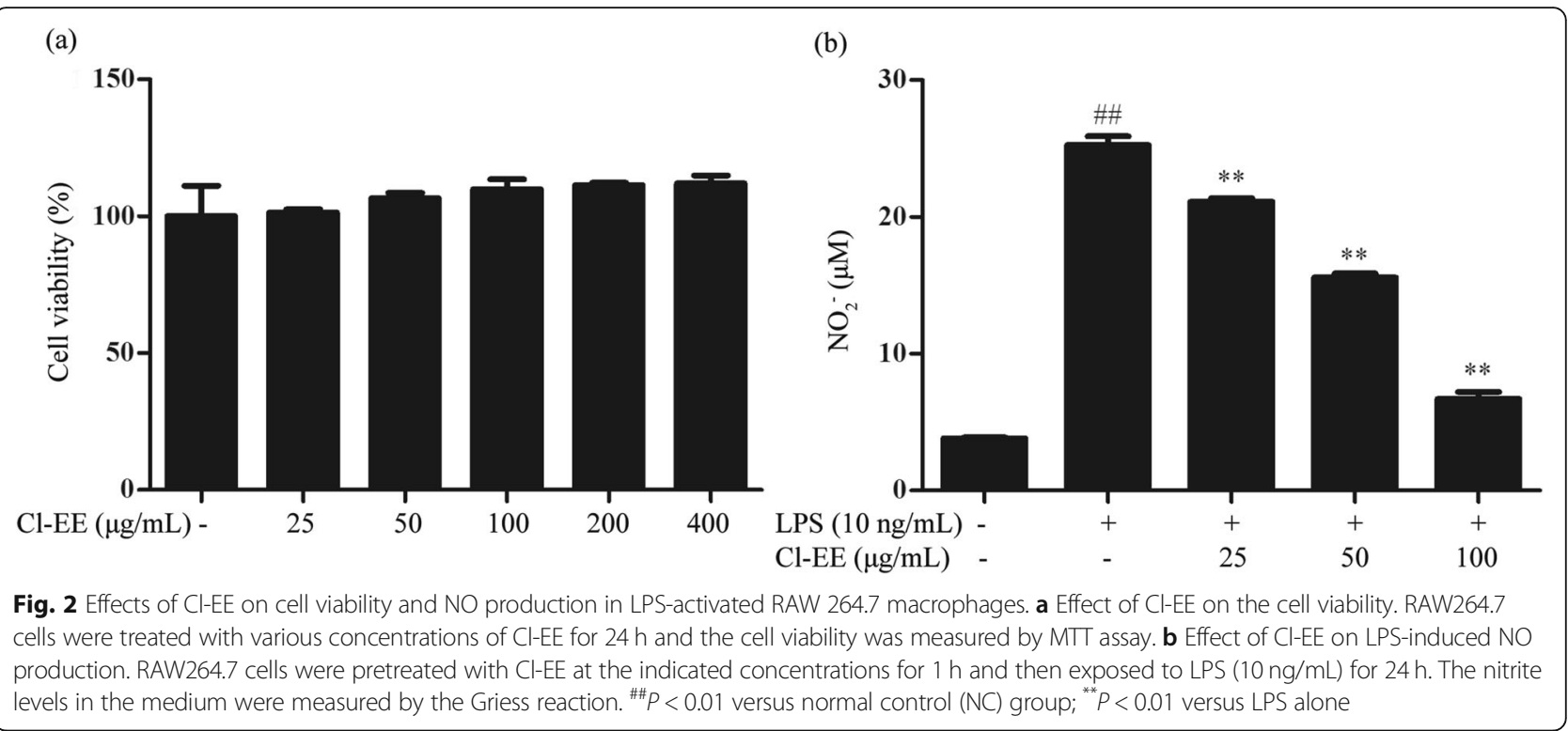

\section{Cl-EE reduces LPS-elevated TNF- $a$, IL-6, MCP-1 and IL-1 $\beta$ expression}

Apart from NO, other proinflammatory cytokines, such as TNF- $\alpha$, MCP-1, IL-6 and IL-1 $\beta$, also play crucial roles in inflammatory processes. Our data showed that Cl-EE concentration-dependently suppressed LPS-elevated supernatant TNF- $\alpha$, MCP-1, IL-6 in RAW 264.7 cells. It also decreased the level of supernatant IL-1 $\beta$ in LPSprimed BMDMs (Fig. 4a and Additional file 3: Table S3). Next, we investigated the effect of Cl-EE on their mRNA levels using RT-PCR. Consistently, Cl-EE also could suppress LPS-induced TNF- $\alpha$, MCP-1, IL- 6 and IL- $1 \beta$ mRNA transcription (Fig. 4b and Additional file 3: Table S3).

\section{Cl-EE has no effect on LPS-activated NF-KB signaling pathway}

As a classical dimeric transcription factor in inflammatory processes, NF- $\mathrm{B}$ can regulate the gene transcription of many proinflammatory mediators [20]. Thus, we investigated the effect of $\mathrm{Cl}-\mathrm{EE}$ on the NF- $\mathrm{BB}$ signaling pathway by using luciferase assay system. The obtained results indicated that $\mathrm{Cl}-\mathrm{EE}$ did not inhibit NF- $\mathrm{KB}-$ dependent transcriptional activity (Fig. 5a and Additional file 4: Table S4). Consistently, Cl-EE little affected the phosphoralation of $I_{\kappa} B \alpha$ and the subsequent nucleus translocation of p65 (Fig. 5b-d and Additional file 4: Table S4).
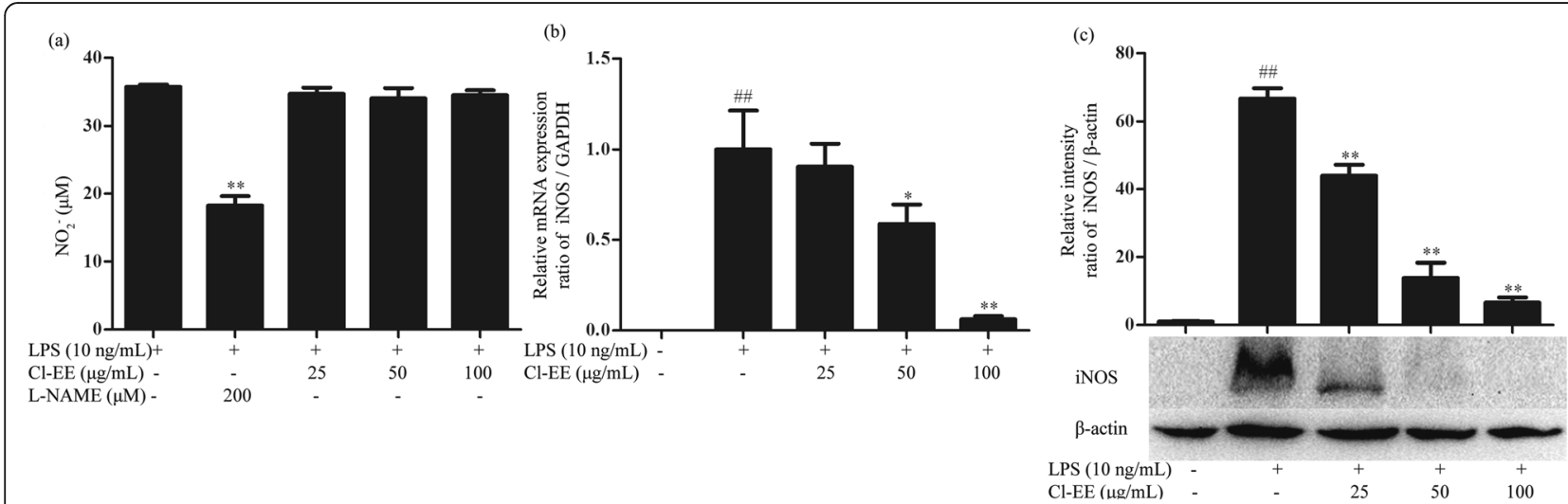

Fig. 3 Effect of Cl-EE on iNOS in LPS-activated RAW264.7 cells. a Effect of Cl-EE on iNOS enzyme activity. RAW264.7 cells were pretreated with LPS $(10 \mathrm{ng} / \mathrm{mL})$ for $12 \mathrm{~h}$ and then exposed to Cl-EE at the indicated concentrations for another $12 \mathrm{~h}$ in the absence of LPS. The nitrite levels in the medium were measured by Griess method. $\mathbf{b}$ Effect of Cl-EE on iNOS mRNA expression. RAW264.7 cells were pretreated with the indicated concentrations of $\mathrm{Cl}$-EE for $1 \mathrm{~h}$ and then exposed to LPS $(10 \mathrm{ng} / \mathrm{mL})$ for $4 \mathrm{~h}$. The mRNA level of iNOS was determined by RT-PCR analysis. $\mathbf{c}$ Effect of Cl-EE on iNOS protein level. RAW264.7 cells were pretreated with Cl-EE at the indicated concentrations for $1 \mathrm{~h}$ and then exposed to LPS (10 ng/mL) for $24 \mathrm{~h}$. Cellular proteins were extracted and the translation level of iNOS was determined by Western blot analysis. ${ }^{\# \#} P<0.01$ versus NC group; ${ }^{*} P<0.05$ and ${ }^{* *} P<0.01$ versus LPS alone 

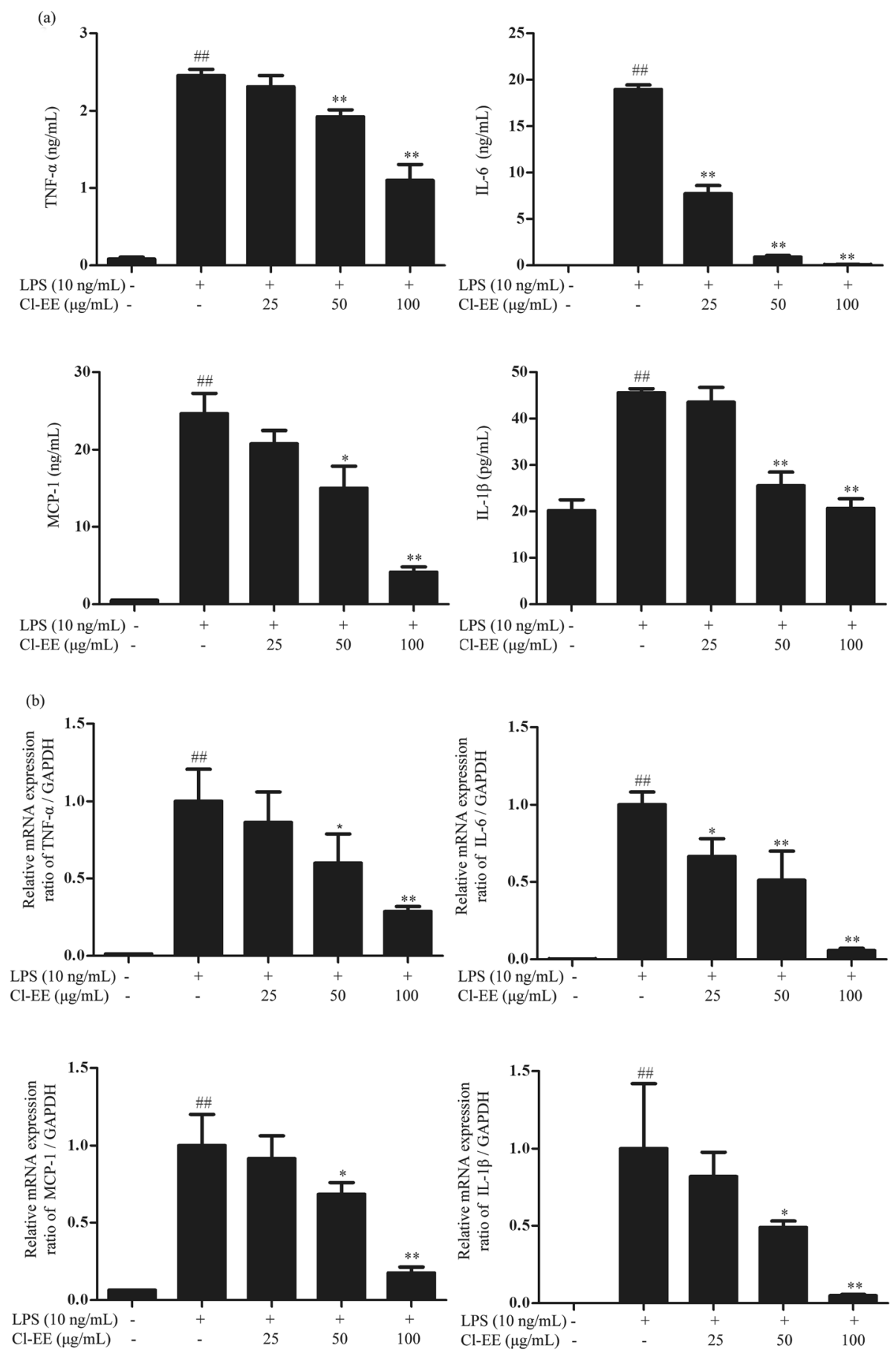

Fig. 4 Effects of $\mathrm{Cl}$-EE on proinflammatory cytokines at transcriptional and translational levels in LPS-activated macrophages. a Effects of Cl-EE on the supernatant proinflammatory cytokines in LPS-activated macrophages. RAW264.7 cells were pretreated with Cl-EE for $1 \mathrm{~h}$ at the indicated concentrations and then exposed to LPS $(10 \mathrm{ng} / \mathrm{mL})$ for TNF-a, IL-6 and MCP-1 determination. BMDMs were pretreated with Cl-EE for $1 \mathrm{~h}$ and then exposed to LPS $(40 \mathrm{ng} / \mathrm{mL})$ for IL-1 $\beta$ assay. The production of TNF-a, IL-6, MCP-1 and IL-1 $\beta$ in the supernatant were determined by ELISA. $\mathbf{b}$ Effects of Cl-EE on the mRNA levels of the proinflammatory cytokines in LPS-activated RAW264.7 cells. Cells were pretreated with Cl-EE at the indicated concentrations for $1 \mathrm{~h}$ and then exposed to LPS $(10 \mathrm{ng} / \mathrm{mL})$ for $4 \mathrm{~h}$. The mRNA expression of TNF-a, IL-6, MCP-1, and IL-1 13 were determined by RT-PCR analysis. ${ }^{\# \#} P<0.01$ versus NC group; ${ }^{*} P<0.05$ and ${ }^{* *} P<0.01$ versus LPS alone 


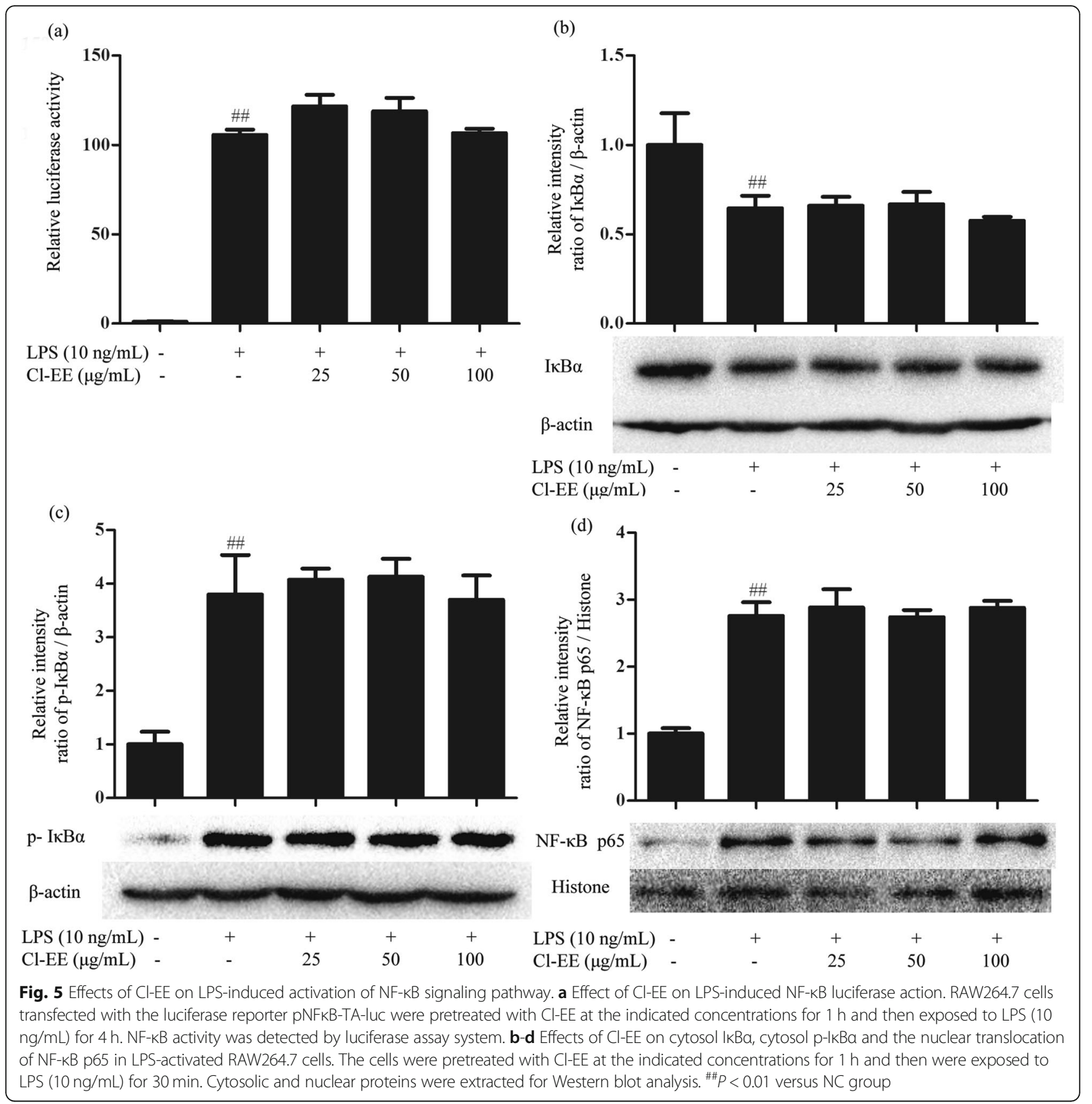

Cl-EE suppresses LPS-induced phosphorylation of ERK1/2 Since Cl-EE had little action on the NF-kB signaling pathway, we next focused on another important signaling pathway-MAPKs, which mainly consisted of three components (ERK1/2, JNK and p38). The results showed that LPS markedly elevated the phosphorylation levels of ERK1/2, JNK and p38, while treatment with Cl-EE significantly reduced $\mathrm{p}$-ERK $1 / 2$ in a concentrationdependent manner without affecting the levels of p-JNK and p-p38 (Fig. 6 and Additional file 5: Table S5).

\section{CI-EE inhibits LPS-elevated circulatory inflammatory cytokines in vivo}

The in vivo anti-inflammatory effect of Cl-EE was evaluated using a mouse endotoxemia model. As shown in Fig. 7 and Additional file 6: Table S6, LPS administration $(1 \mathrm{mg} / \mathrm{kg}$, i.v.) markedly increased serum TNF- $\alpha$, IL-6 and MCP-1 levels compared with the NC group, while pretreatment with $\mathrm{Cl}-\mathrm{EE}$ (75, 150 and $300 \mathrm{mg} / \mathrm{kg}$, i.p.) decreased the production of these inflammatory cytokines dose-dependently. 

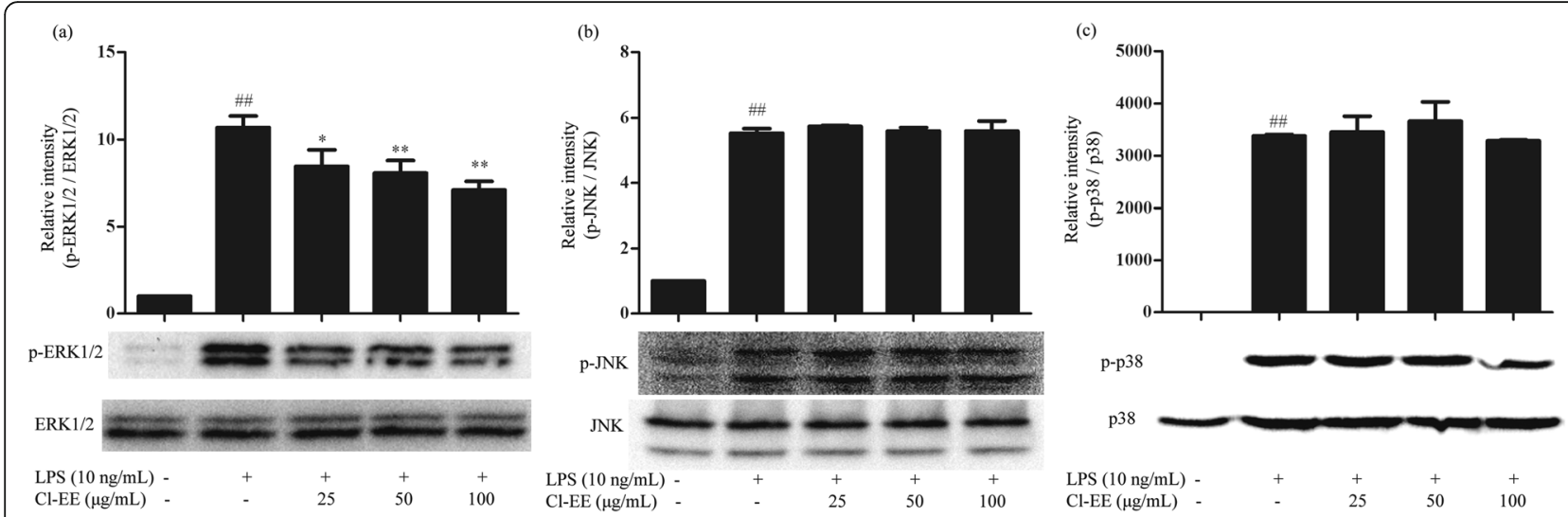

Fig. 6 Effects of Cl-EE on LPS-induced phosphorylation of MAPKs. a ERK1/2, b JNK, and c p38. RAW264.7 cells were pretreated with Cl-EE at the indicated concentrations for $1 \mathrm{~h}$ and then exposed to LPS (10 ng/mL) for $15 \mathrm{~min}$. Total proteins were extracted for Western blot analysis. ${ }^{\#} P<$ 0.01 versus NC group; ${ }^{*} P<0.05$ and ${ }^{* *} P<0.01$ versus LPS alone

\section{Discussion}

The herb of $C$. lucidissima has been widely used to treat inflammatory diseases as Zhuang folk medicine in south of China, especially in Guangxi and Guizhou provinces. Although C. lucidissima is considered to be a potent anti-inflammatory herb, its underlying mechanism remains unknown. To this end, we explored the antiinflammatory activities and the mechanism of C. lucidissima using the LPS-stimulated macrophages and mouse endotoxemia model. To our knowledge, the traditional extract way of C. lucidissima includes water decoction (high-polar molecular-rich), vinum (both high- and lowpolar molecule-rich) and oil (low-polar molecule-rich). In a limited number of chemical researches, low-polar xanthones were found to have definite antiinflammatory activity [11]. Together with our preliminary experiment, we extracted C. lucidissima by $85 \%$ ethanol to enrich the main anti-inflammatory ingredients in the present study. The obtained extract (Cl-EE) was firstly evaluated the cytotoxic effect on macrophages using MTT assay. The data showed that Cl-EE did not affect cell viability up to $400 \mu \mathrm{g} / \mathrm{mL}$ (Fig. 2a and
Additional file 1: Table S1). Thus, we selected 25, 50, $100 \mu \mathrm{g} / \mathrm{mL}$ of $\mathrm{Cl}-\mathrm{EE}$ in the in vitro experiments.

Diffusible micromolecule NO plays an important role in maintaining the homeostasis of the immune system, while excessive $\mathrm{NO}$ is associated with the initiation of inflammatory diseases [21]. In the present study, supernatant $\mathrm{NO}$ was potently decreased by Cl-EE in a concentration-dependent manner in LPS-activated RAW264.7 cells (Fig. 2b and Additional file 1: Table S1). During the inflammatory processes, large amounts of $\mathrm{NO}$ are generated by iNOS in macrophages [22]. Our data showed that Cl-EE down-regulated iNOS transcriptional and translational levels without inhibiting its activity (Fig. 3 and Additional file 2: Table S2).

Apart from NO, other proinflammatory cytokines, such as TNF- $\alpha$, IL-6, MCP- 1 and IL- $1 \beta$, also play essential roles in the inflammatory processes. TNF- $\alpha$ is an important cytotoxic mediator that can lead to tissue destruction, cytotoxicity, and acute inflammation. IL-6 is regarded as an endogenous mediator of LPS-induced fever [23] and IL-1 $\beta$ can initiate and enhance the inflammatory response [24]. MCP-1, a CC-chemokine, triggers

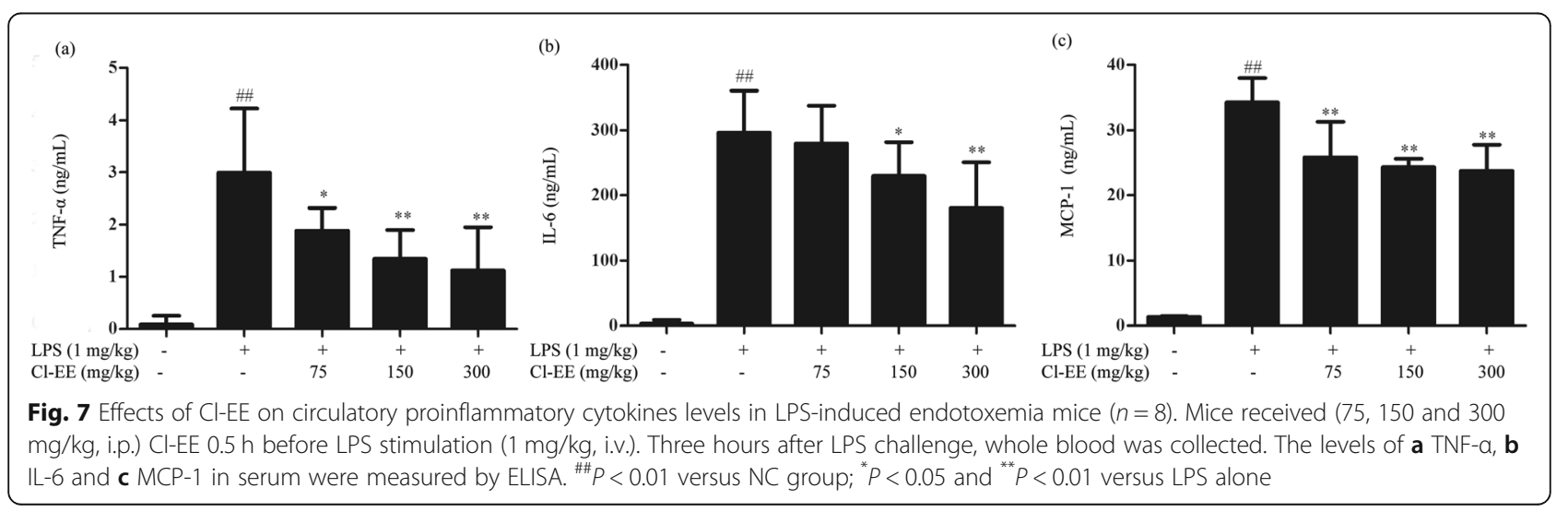


inflammation process including leukocyte attachment to endothelium and recruitment to inflammation site [25]. Our data showed that Cl-EE effectively suppressed the levels of these inflammatory cytokines in the supernatant of LPS-activated macrophages (Fig. 4a and Additional file 3: Table S3), showing a multifaceted action. Consistently, their mRNA levels were also down-regulated by Cl-EE (Fig. 4b and Additional file 3: Table S3).

$\mathrm{NF}-\mathrm{KB}$ is a classical signaling pathway in the regulation of the production of proinflammatory mediators, which depends on the phosphorylation and degradation of ІкB [26]. As one member of NF-kB family, p65 has a Cterminal transactivation domain that has intrinsic ability to activate transcription. In this study, the elevated levels of p-IkB $\alpha$ (cytosol) and p65 (nuclear) by LPS were not suppressed by Cl-EE (Fig. 5b-d and Additional file 4: Table S4). Consistently, in the luciferase reporter gene assay, Cl-EE did not affect the NF- $\mathrm{KB}$ transcriptional activity (Fig. 5a and Additional file 4: Table S4), suggesting that the anti-inflammatory effect of Cl-EE was not attributed to inhibiting the activation of NF- $\mathrm{kB}$ signal.

AP-1, another conventional transcription factor, acts downstream of MAPKs which consists of three components, JNK, ERK1/2 and p38. Activated MAPKs are able to phosphorylate their respective substrate proteins, thus initiate proinflammatory cytokines transcription [27]. In our study, Cl-EE selectively diminished LPS-induced phosphorylation of ERK1/2 but did not affect the phosphorylation levels of JNK and p38 (Fig. 6 and Additional file 5: Table S5).

Endotoxemia is a systemic response to serious infection and yields a poor prognosis when it is associated with organ dysfunction, hypoperfusion, or hypotension [28]. It is also associated with cytokines storm characterized by the upregulation of proinflammatory cytokines [29]. Therefore, we evaluated whether Cl-EE could attenuate LPS-caused endotoxemia. In line with our findings in vitro, Cl-EE indeed decreased LPS-induced circulatory inflammatory mediators release (TNF- $\alpha$, IL-6 and MCP-1) (Fig. 7 and Additional file 6: Table S6).

\section{Conclusions}

In summary, our findings demonstrated that the antiinflammatory activity of Cl-EE was attributed to attenuating the phosphorylation of ERK1/2, thereby suppressing iNOS, TNF- $\alpha$, MCP-1, IL- 6 and IL- $1 \beta$ at transcriptional and translational levels in LPS-activated macrophages. Meanwhile, Cl-EE could lower LPS-elevated circulatory inflammatory cytokines in vivo.

\section{Supplementary information}

Supplementary information accompanies this paper at https://doi.org/10. 1186/s12906-019-2783-2.

Additional file 1: Table S1. Raw data for Fig. 2.
Additional file 2: Table S2 Raw data for Fig. 3.

Additional file 3: Table S3 Raw data for Fig. 4.

Additional file 4: Table S4 Raw data for Fig. 5.

Additional file 5: Table S5 Raw data for Fig. 6.

Additional file 6: Table S6 Raw data for Fig. 7.

\section{Abbreviations}

BMDMs: Bone marrow-derived macrophages; C. lucidissima: Canscora lucidissima; Cl-EE: Ethanol extract of C. lucidissima; IKK: Inhibitor of KB kinase; iNOS: inducible nitric oxide synthase; L-NAME: L-NG-nitroarginine methyl ester; LPS: Lipopolysaccharide; MTT: 3-(4,5-dimethylthiazol-2-yl)-2,5-diphenyl tetrazolium bromide; NC: Normal control; p-ERK1/2: phospho-ERK1/2; pIkBa: phospho-IkBa; p-JNK: phospho-JNK; p-p38: phospho-p38. RT-PCR: realtime PCR.

\section{Acknowledgements}

We would like to express our sincere gratitude to Prof. Yun-feng Huang from the Guangxi Institute of Chinese Medicine \& Pharmaceutical Sciences for assisting with the plant collection, authentication and voucher specimen deposition.

\section{Authors' contributions}

$Y Q$ and $Y G$ designed the study and modified the manuscript. QLF and YG performed the main experiments. QLF wrote the manuscript. XYZ and RJQ revised the manuscript. YFH provided the plant materials. XYZ and RJQ performed the extracts preparation. YXH and XML analyzed the data. RLC drafted all figures and tables. All authors read and approved the final version of the manuscript.

\section{Funding}

This work was supported by Chinese Academy of Medical Sciences (CAMS) Innovation Fund for Medical Sciences (CIFMS) (2016-12M-3-015) and National Natural Science Foundation of China (Nos. 81601385 and 81873066). The funders had no role in study design, data collection and analysis, decision to publish, or preparation of the manuscript.

\section{Availability of data and materials}

The datasets used and analysed during the current study are available from the corresponding author on reasonable request.

\section{Ethics approval}

All the animal experiments were carried out according to the National Institutes of Health Guide for Care and Use of Laboratory Animals and approved by the Animals Ethics Committee of the IMPLAD of Chinese Academy of Medical Sciences (CAMS).

Consent for publication

Not applicable.

\section{Competing interests}

The authors declare that they have no competing interests.

\section{Author details}

${ }^{1}$ Institute of Medicinal Plant Development, Chinese Academy of Medical Sciences and Peking Union Medical College, 151 North Ma Lian Wa Road, Haidian District, Beijing 100193, China. ${ }^{2}$ Guangxi Institute of Chinese Medicine and Pharmaceutical Sciences, Nanning, China.

Received: 23 September 2019 Accepted: 29 November 2019 Published online: 16 December 2019

\section{References}

1. Lin MW, Tsao LT, Chang LC, Chen YL, Huang L, Kuo SC, Tzeng CC, Lee MR, Wang JP. Inhibition of lipopolysaccharide-stimulated NO production by a novel synthetic compound CYL-4d in RAW 264.7 macrophages involving the blockade of MEK4/JNK/AP-1 pathway. Biochem Pharmacol. 2007;73: 1796-806.

2. Baggiolini M. Chemokines and leukocyte traffic. Nature. 1998;392:565-8. 
3. Fontaine C, Rigamonti E, Nohara A, Gervois P, Teissier E, Fruchart JC, Staels $B$, Chinetti-Gbaguidi $G$. Liver $X$ receptor activation potentiates the lipopolysaccharide response in human macrophages. Circ Res. 2007;101: 40-9.

4. Palsson-McDermott EM, O'Neill LA. Signal transduction by the lipopolysaccharide receptor, toll-like receptor-4. Immunology. 2004;113: 153-62.

5. Zandi E, Chen Y, Karin M. Direct phosphorylation of IkappaB by IKKalpha and IKKbeta: discrimination between free and NF-kappaB-bound substrate. Science. 1998:281:1360-3.

6. Lawrence T, Bebien M, Liu GY, Nizet V, Karin M. IKK alpha limits macrophage NF-kappaB activation and contributes to the resolution of inflammation. Nature. 2005;434:1138-43.

7. Lang V, Janzen J, Fischer GZ, Soneji Y, Beinke S, Salmeron A, Allen H, Hay RT, Ben-Neriah Y, Ley SC. bTrCP-mediated proteolysis of NF-KB1 p105 requires phosphorylation of p105 serines 927 and 932. Mol Cell Biol. 2003; 23:402-13.

8. Beinke S, Robinson MJ, Salmeron A, Hugunin M, Allen H, Ley SC. Lipopolysaccharide activation of the TPL-2/MEK/extracellular signal-regulated kinase mitogen activated protein kinase cascade is regulated by IKB kinaseinduced proteolysis of NF-kB1 p105. Mol Biol Cell. 2004:24:9658-67.

9. Tiwari M, Dwivedi UN, Kakkar P. Suppression of oxidative stress and proinflammatory mediators by Cymbopogon citratus D. Stapf extract in lipopolysaccharide stimulated murine alveolar macrophages. Food Chem Toxicol. 2010;48:2913-9.

10. Chinese Materia Medica Commission of State Administration of Traditional Chinese Medicine. Chinese Materia Medica. Shanghai: Shanghai Science and Technology Press; 1999.

11. Yang D, Xu S. The primary study on the anti-inflammatory and toxicity effects of xanthones in Canscora lucidissima. Acad J Guangdong Coll Pharm. 2001;1:33-5.

12. Madan B, Mandal BC, Kumar S, Ghosh B. Canscora decussata (Roxb.) Schult (Gentianaceae) inhibits LPS-induced expression of ICAM-1 and E-selectin on endothelial cells and carageenan-induced paw-edema in rats. J Ethnopharmacol. 2003;89:211-6.

13. Celada A, Gray PW, Rinderknecht E, Schreiber RD. Evidence for a gammainterferon receptor that regulates macrophage tumoricidal activity. J Exp Med. 1984;160:55-74.

14. Kim SA, Kim YC, Kim SW, Lee SH, Min JJ, Ahn SG, Yoon JH. Antitumor activity of novel indirubin derivatives in rat tumor model. Clin Cancer Res. 2007;13:253-9.

15. Gao Y, Liu F, Fang L, Cai RL, Zong CJ, Qi Y. Genkwanin inhibits proinflammatory mediators mainly through the regulation of miR-101/MKP1/MAPK pathway in LPS-activated macrophages. PLoS One. 2014;9:e96741.

16. Chen X, Zong C, Gao Y, Cai R, Fang L, Lu J, Liu F, Qi Y. Curcumol exhibits anti-inflammatory properties by interfering with the JNK-mediated AP-1 pathway in lipopolysaccharide-activated RAW264.7 cells. Eur J Pharmacol. 2014;723:339-45.

17. Li M, Zhang L, Cai RL, Gao Y, Qi Y. Lipid-soluble extracts from Salvia miltiorrhiza inhibit production of LPS-induced inflammatory mediators via NF-KB modulation in RAW 264.7 cells and perform antiinflammatory effects in vivo. Phytother Res. 2012;26:1195-204.

18. Hsu BG, Yang FL, Lee RP, Peng TC, Chen HI. Effects of post-treatment with low-dose propofol on inflammatory responses to lipopolysaccharideinduced shock in conscious rats. Clin Exp Pharmacol Physiol. 2005;32:24-9.

19. Pinho $B R$, Sousa $C$, Valentão $P$, Andrade $P B$. Is nitric oxide decrease observed with naphthoquinones in LPS stimulated RAW 264.7 macrophages a beneficial property? PLoS One. 2011;6:e24098.

20. Vaillancourt F, Morquette B, Shi Q, Fahmi H, Lavigne P, Di Battista JA, Fernandes JC, Benderdour M. Differential regulation of cyclooxygenase-2 and inducible nitric oxide synthase by 4-hydroxynonenal in human osteoarthritic chondrocytes through ATF-2/CREB-1 transactivation and concomitant inhibition of NF-kappaB signaling cascade. J Cell Biochem. 2007;100:1217-31.

21. Ochoa JB, Udekwu AO, Billiar TR, Curran RD, Cerra FB, Simmons RL, Peitzmanet $A B$. Nitrogen oxide levels in patients after trauma and during sepsis. Ann Surg. 1991;214:621-6.

22. Lee SH, Soyoola E, Chanmugam P, Hart S, Sun W, Zhong H, Liou S, Simmons D, Hwang D. Selective expression of mitogen-inducible cyclooxygenase in macrophages stimulated with lipopolysaccharide. J Biol Chem. 1992;267:25934-8
23. Neta R, Vogel SN, Sipe JD, Wong GG, Nordan RP. Comparison of in vivo effects of human recombinant IL 1 and human recombinant IL 6 in mice. Lymphokine Res. 1988;7:403-12.

24. El-Omar EM, Carrington M, Chow WH, McColl KE, Bream JH, Young HA, Herrera J, Lissowska J, Yuan CC, Rothman N, Lanyon G, Martin M, Fraumeni JF Jr, Rabkin CS. Interleukin-1 polymorphisms associated with increased risk of gastric cancer. Nature. 2000;404:398-402.

25. Armstrong EJ, Morrow DA, Sabatine MS. Inflammatory biomarkers in acute coronary syndromes: part I: introduction and cytokines. Circulation. 2006; 113:e72-5.

26. Gantke T, Sriskantharajah S, Sadowski M, Ley SC. IKB kinase regulation of the TPL-2/ERK MAPK pathway. Immunol Rev. 2012;246:168-82.

27. Weinstein SL, Sanghera JS, Lemke K, DeFranco AL, Pelech SL. Bacterial lipopolysaccharide induces tyrosine phosphorylation and activation of mitogen-activated protein kinases in macrophages. J Biol Chem. 1992;267: 14955-62.

28. Cohen J. The immunopathogenesis of sepsis. Nature. 2002;420:885-91.

29. Bhatia M, He M, Zhang H, Moochhala S. Sepsis as a model of SIRS. Front Biosci. 2009;14:4703-11.

\section{Publisher's Note}

Springer Nature remains neutral with regard to jurisdictional claims in published maps and institutional affiliations.

\section{Ready to submit your research? Choose BMC and benefit from:}

- fast, convenient online submission

- thorough peer review by experienced researchers in your field

- rapid publication on acceptance

- support for research data, including large and complex data types

- gold Open Access which fosters wider collaboration and increased citations

- maximum visibility for your research: over $100 \mathrm{M}$ website views per year

At BMC, research is always in progress.

Learn more biomedcentral.com/submissions 